L'éducation des filles nobles en Europe, XVII ${ }^{\mathrm{e}}-\mathrm{XVIII}{ }^{\mathrm{e}}$ siècles, sous la direction de Chantal Grell et Armand Ramière De Fortanier

\title{
Laura Colombo
}

\section{OpenEdition}

Journals

\section{Édition électronique}

URL : http://journals.openedition.org/studifrancesi/9542

DOI : 10.4000/studifrancesi.9542

ISSN : 2421-5856

Éditeur

Rosenberg \& Sellier

\section{Édition imprimée}

Date de publication : 1 décembre 2007

Pagination : 658

ISSN : 0039-2944

\section{Référence électronique}

Laura Colombo, "L'éducation des filles nobles en Europe, $x v I^{\mathrm{e}}$-xvII ${ }^{\mathrm{e}}$ siècles, sous la direction de Chantal Grell et Armand Ramière De Fortanier », Studi Francesi [En ligne], 153 (LI | III) | 2007, mis en ligne le 30 novembre 2015, consulté le 10 janvier 2021. URL : http://journals.openedition.org/studifrancesi/9542 ; DOI : https://doi.org/10.4000/studifrancesi.9542

Ce document a été généré automatiquement le 10 janvier 2021.



Studi Francesi è distribuita con Licenza Creative Commons Attribuzione - Non commerciale - Non opere derivate 4.0 Internazionale. 


\title{
L'éducation des filles nobles en Europe, $\mathrm{XVII}{ }^{\mathrm{e}}-\mathrm{XVIII}{ }^{\mathrm{e}}$ siècles, sous la direction de Chantal Grell et Armand Ramière De Fortanier
}

\author{
Laura Colombo
}

\section{RÉFÉRENCE}

L'éducation des filles nobles en Europe, XVII ${ }^{e}$-XVIII ${ }^{e}$ siècles, sous la direction de Chantal GRELL et Armand RAMIÈRE De fORTANIER, Paris, Presses de l'Université Paris-Sorbonne, 2005, pp. 218.

1 En 1999, une exposition à la Grande Ecurie du Roi à Versailles évoquait le monde fascinant et caché des demoiselles de Saint-Cyr. Un catalogue, précieux, en perpétuait la mémoire, suivi d'un colloque et de ce volume, qui élargit les recherches sur l'éducation des jeunes filles nobles à l'Europe, y compris la Russie, du point de vue des institutions créées à cette fin. S'ouvre alors un panorama riche en détails historiques, mais également géographiques et sociaux, à partir d'un historique des traités d'éducation, prenant en compte les variations de l'alphabétisation et l'éternel débat sur l'«accès des femmes à la culture», avec un examen de «l'héritage du Grand Siècle» en France et Angleterre (Chantal Grell, France et Angleterre: l'héritage du Grand Siècle, pp. 9-31).

2 Saint-Cyr est naturellement le modèle et la pierre de touche pour toute institution visant à instruire les jeunes filles des familles distinguées; beaucoup d'interventions étudient en effet ce "haut lieu voué à l'éducation», pour en évoquer l'histoire et la structure, autant que la «pédagogie réaliste» qui y était pratiquée (Jean-Joseph MILHET, Saint-Cyr: haut lieu voué à l'éducation, pp. 99-106), mais aussi pour analyser les «origines géographiques» des élèves (Dominique Picco, Origine géographique des Demoiselles de 
Saint-Cyr, pp. 107-126). Le rôle de Saint-Cyr, on s'en doutait bien, fut aussi «politique», et voilà la «vertu féminine» mise en rapport avec l'«évolution des notions de citoyenneté au XVIII ${ }^{\mathrm{e}}$ siècle» (Karen L. TAYLOR, Saint-Cyr, vertu féminine et évolution des notions de citoyenneté au XVIII siècle, pp. 127-144), ainsi qu'avec son rayonnement au niveau européen. Le lecteur trouvera ainsi des témoignages sur les jeunes filles musiciennes des quatre Ospedali de Venise (Giuseppe ELLERO, Les demoiselles de Saint-Cyr et les jeunes filles musiciennes des quatre Ospedali de Venise, pp. 31-38), très utiles pour les sandistes relisant Consuelo, ainsi que sur les institutions protestantes des petits états allemands (Lucia косн, «D'excellents ateliers et écoles...» Les fondations protestantes comme lieu d'enseignement pour les femmes à l'époque moderne. Exemple des comtés de Nassau entre 1550 et 1650, pp. 43-58, et Klaus MALETTKE, L'éducation des jeunes filles nobles et la chevalerie dans les Landgraviats de Hesse Cassel et de Hesse-Darmstadt, pp. 59-73). Une partie importante du volume est faite à la Pologne (Maciej SERWANSKI, Les formes d'éducation des filles nobles en Pologne aux XVI, XVII et XVIII siècles, pp. 75-86 et Igor KRASZEWSK, L'école cracovienne des Sceurs de la Présentation et la noblesse polonaise aux XVII et XVIII siècles, pp. 87-98), sans oublier cependant la Russie. Les communications de Maciej FORICKI (Denis Diderot et le Saint-Cyr saint-petersbourgeois, pp. 145-156), et de Wladimir TROUBEZKOY (Quelques smolianski et une saint-cyrienne imaginaire, pp. 157-166) portent sur l'Institut Smolny qui, voulu par Catherine et dirigé pour un certain temps par Diderot, reprit les traditions, même théâtrales, de Saint-Cyr, et donna naissance à «une nouvelle espèce sociale», en formant «des jeunes femmes comme on n'en avait jamais vu en Russie» (p. 161).

3 Ces études retracent l'histoire de cette éducation qui se voulait «éclairée» et qui passait par un programme pédagogique déléguant aux jeunes filles les responsabilités les plus fondamentales de la maison, ainsi que la patrie affective, voire «artistique» de la vie familiale, tout en leur niant une éducation vraiment savante. En instituant une «révolution conservatrice» (p. 160), ce système éducatif créait une tension entre une indubitable instance de progrès et une perpétuation de l'ordre social. Précieux pour les historiens, qui y puiseront maintes informations intéressantes, et pour les littéraires, qui y verront une source de ce qui, de l'histoire des idées, passe dans la littérature, ce volume est aussi un hommage rendu à ces demoiselles qui, depuis les «Zitelles» vénitiennes jusqu'aux pensionnaires de Saint-Cyr ont elles aussi engendré l'Europe moderne. 